ORIGINAL ARTICLE

\title{
Bid can mediate a pro-apoptotic response to etoposide and ionizing radiation without cleavage in its unstructured loop and in the absence of p53
}

\author{
C Maas, E de Vries, SWG Tait ${ }^{1}$ and J Borst \\ Division of Immunology, The Netherlands Cancer Institute, Amsterdam, The Netherlands
}

BH3-only protein Bid is a key player in death receptorinduced apoptosis, because it provides the link with the mitochondrial route for caspase activation. In this pathway, Bid is activated upon cleavage by caspase-8. Its BH3 domain-containing carboxy-terminal fragment subsequently provokes mitochondrial outer membrane permeabilization by Bak/Bax activation. Bid has also been implicated in the apoptotic response to ionizing radiation (IR) and the topoisomerase inhibitor etoposide, anti-cancer regimens that cause double-strand (ds)DNA breaks. We confirm the existence of this pathway and show that it is p53-independent. However, the degree of Bid participation in the apoptotic response to dsDNA breaks depends on the nature of cell transformation. We used Bid-deficient mouse embryonic fibroblast (MEF) lines that were reconstituted with Bid to control the cellular background and demonstrated that the Biddependent apoptotic pathway induced by IR and etoposide operates in MEFs that are transformed by SV40, but is not evident in E1A/Ras-transformed MEFs. The Bid-dependent apoptotic response in p53-deficient SV40transformed MEFs contributed to clonogenic execution of the cells, implying relevance for treatment outcome. In these cells, Bid acted in a conventional manner in that it required its $\mathrm{BH} 3$ domain to mediate apoptosis in response to IR and etoposide, and triggered apoptotic execution by indirect activation of Bak/Bax, mitochondrial permeabilization and caspase-9 activation. However, the mechanism of Bid activation was unconventional, because elimination of all known or suspected cleavage sites for caspases or other proteolytic enzymes and even complete elimination of its unstructured cleavage loop left Bid's pro-apoptotic role in the response to IR and etoposide unaffected.

Oncogene (2011) 30, 3636-3647; doi:10.1038/onc.2011.75; published online 21 March 2011

Keywords: Bid; apoptosis; DNA damage; p53

Correspondence: Professor J Borst, Division of Immunology, The Netherlands Cancer Institute, Plesmanlaan 121, Amsterdam 1066 CX, The Netherlands.

E-mail: j.borst@nki.nl

${ }^{1}$ Current address: Department of Immunology, St Jude Children's Research Hospital, Memphis, TN 38105, USA.

Received 11 May 2010; revised and accepted 8 February 2011; published online 21 March 2011
Introduction

DNA-damaging regimens can limit the clonogenicity of tumor cells via irreversible cell cycle arrest, mitotic catastrophe or apoptosis (Brown and Wouters, 1999; Schmitt et al., 2000). The apoptotic response to DNA damage relies on $\mathrm{Bcl}-2$ family members, with $\mathrm{BH} 3$-domain only proteins and $\mathrm{Bak} / \mathrm{Bax}$ acting in a pro-apoptotic manner and inhibitory Bcl-2 family counteracting their activity. Upon apoptotic stimulation, BH3-only proteins translocate to the mitochondria, where they activate Bax and/or Bak that enable mitochondrial outer membrane permeabilization (MOMP). This releases cytochrome $c$, Smac/DIABLO and HtrA2/Omi into the cytosol, resulting in the activation of caspase-9 and effector caspases, and apoptotic execution (Wang, 2001).

The p53 tumor suppressor protein has an important role in the apoptotic response to DNA damage. It may directly activate Bax/Bak at the mitochondria and acts as a transcription factor to direct the expression of apoptotic mediators (Chipuk and Green, 2006). These include the BH3-only proteins Puma, Noxa and Bid, as well as Bax and Apaf-1, all of which contribute to the mitochondrial apoptosis pathway. Analysis of Puma- or Noxa-deficient mice corroborated the role of these BH3only proteins in p53-dependent apoptosis (Villunger et al., 2003). Side-by-side analysis of the responsiveness of $p 53^{-1-}$, puma $^{-1-}$, noxa $a^{-1-}$ and puma;noxa ${ }^{-1-}$ cells to ionizing radiation (IR) and etoposide furthermore indicated that Puma and Noxa are the main effectors of p53-dependent DNA-damage-induced apoptosis in lymphoid cells and transformed mouse embryonic fibroblasts (MEFs), with Puma having the dominant role (Michalak et al., 2008). However, the combined deletion of Puma and Noxa did not always offer the same level of protection as p53, implicating other p53regulated $\mathrm{BH} 3$-only proteins. Moreover, p53-mutant cells can also undergo DNA-damage-induced apoptosis (Strasser et al., 1994) and the question is which BH3only proteins activate the mitochondria in that case. Expression of Puma by genotoxic stimuli is strictly p53-dependent, but that of Noxa is not (Yu et al., 2001; Ploner et al., 2008), while Bid is constitutively expressed in many normal and tumor cell types (Krajewska et al., 2002). Therefore, both Noxa and Bid, but possibly also other BH3-only proteins, may contribute to DNAdamage-induced apoptosis in p53 wild-type (WT) or mutant cells. Indeed, in cerebellar neurons, only the 
combined deletion of Puma, Bid and Bim prevented IR-induced apoptosis (Ren et al., 2010).

$\mathrm{Bid}$ is the requisite $\mathrm{BH} 3$-only protein that connects death receptors to the mitochondrial route for caspase activation. In this pathway, Bid is activated upon proteolytic cleavage in its unstructured loop by caspase-8 (Luo et al., 1998). This cleavage facilitates mitochondrial association of the cleaved Bid complex by exposing a glycine residue that becomes myristoylated (Zha et al., 2000). Moreover, it triggers ubiquitination and degradation of the N-terminal fragment of Bid, thus liberating the $\mathrm{BH} 3$ domain in the C-terminal fragment to perform its pro-apoptotic function (Tait et al., 2007). Early studies suggested that Bid can also contribute to DNA damage-induced apoptosis: Primary $\mathrm{Bid}^{-1-}$ MEFs were less sensitive to adriamycin- and 5-fluorouracil-induced apoptosis than WT MEFs (Sax et al., 2002) and introduction of Bid sensitized primary $\mathrm{Bid}^{-1-}$ MEFs to ultraviolet-, etoposide- and cisplatininduced apoptosis (Sarig et al., 2003). Because Bid can be cleaved by effector caspases and can participate in a feed-forward loop for MOMP (Slee et al., 2000), it is important to assess whether Bid has the primary role in $\mathrm{Bax} / \mathrm{Bak}$ activation in such cases. We have demonstrated that Bid was indeed responsible for the primary induction of MOMP upon treatment with IR or etoposide in p53-mutant Jurkat $\mathrm{T}$ leukemic cells (Werner et al., 2004).

A prominent study confirmed a role for Bid in the apoptotic response to DNA damage. In telomerase (hTERT)-immortalized $\mathrm{Bid}^{-1-} \mathrm{MEFs}$, WT Bid reconstitution restored the defective apoptotic response to IR and etoposide to WT levels. Bid acted as a sensor of doublestrand (ds)DNA breaks, as it was phosphorylated by Ataxia Telangiectasia, mutated (ATM) when cells were treated with IR or etoposide. This triggered an unsuspected function of Bid in S-phase arrest, which was hypothesized to favor DNA repair and cell survival (Kamer et al., 2005). Bid was therefore proposed to have a dual role in the response to dsDNA breaks: promotion of repair by a delay in S-phase progression, followed by apoptosis in case repair is insufficient (Gross, 2006). Related work used immortalized myeloid progenitor cells to demonstrate Bid's pro-survival role in S-phase arrest, which proved BH3-domain independent (Zinkel et al., 2005). However, an independent study, in which cells from newly developed $\mathrm{Bid}^{-1-}$ mice were extensively examined, failed to reveal either a pro-apoptotic or a pro-survival role for Bid in the DNA-damage response (Kaufmann et al., 2007). The ensuing debate centered in part on the cell types that had been used for analysis, their genetic background, cell cycle status and/or transformed state, because these might provide clues for the discrepant outcome of the studies (Zinkel et al., 2007).

We demonstrate that $\mathrm{Bid}$ can indeed be the requisite apoptotic mediator in response to dsDNA damage, but its participation depends on the nature of cell transformation. SV40-transformed MEFs required Bid for IR-, but not etoposide-induced apoptosis, while downregulation of $\mathrm{p} 53$ rendered them fully reliant on Bid for induction of apoptosis and clonogenic execution by both
IR and etoposide. E1A/Ras-transformed MEFs, however, did not employ this pathway, either in the presence or in the absence of p53. Bid acted conventionally in the p53-independent apoptotic response to IR and etoposide in that it required its $\mathrm{BH} 3$ domain and executed the cells via Bak/Bax-dependent MOMP and caspase- 9 activation. The mechanism of Bid activation by DNA-damaging regimens was unconventional though, because extensive mutation analysis demonstrated that it was fully independent of proteolytic cleavage in its unstructured loop and even proceeded normally when the loop was deleted.

\section{Results}

Bid can convey the apoptotic response to etoposide and $I R$, in a p53-independent manner

We found previously that Bid was required for IR- and etoposide-induced apoptosis in p53 mutant Jurkat T leukemic cells (Werner et al., 2004). Therefore, we hypothesized that the p53 status might dictate whether cells depend on Bid for their apoptotic response to dsDNA damage. To examine this, we used immortalized MEFs as a cellular model, to match earlier studies (Kamer et al., 2005; Zinkel et al., 2005). Bid ${ }^{-/-}$MEFs that had been transformed with the whole genome of SV40 were stably transduced with an empty RNA interference (RNAi) vector (EV1) or with a vector encoding p53 short hairpin (sh)RNA to create p53proficient (control) and p53-deficient (p53-RNAi) variants of the same cells. These cell lines were stably transduced with a Bid expression vector or with the empty vector (EV2) to have each cell line in a WT Bid or $\mathrm{a} \mathrm{Bid}^{-/-}$version. The lines were created in parallel in the same time frame. This well-controlled set-up excluded differences between experimental groups that were due to the genetic background of the cells, the process of retroviral transduction or other variables not related to expression of Bid or p53. Immunoblotting showed that the starting population of $\mathrm{Bid}^{-/-}$MEFs expressed p53 and lacked Bid. It also validated silencing of p53 and expression of $\mathrm{Bid}$ in the relevant transduced cells (Figure 1a). Moreover, immunoblotting for Bim, Puma, Mcl-1, Bcl-2, Bcl- $\mathrm{x}_{\mathrm{L}}$ and Bcl-W showed that their expression was comparable in p53 RNAi Bid ${ }^{-1-}$ MEFs with and without exogenous Bid (Supplementary Figure 1). The cell lines were treated with etoposide or IR at different doses and analyzed for their apoptotic response after 24 or $48 \mathrm{~h}$, respectively. Apoptosis was read out by flow cytometry as the percentage of cells with cleaved caspase-3. The control $\mathrm{Bid}^{-/-} \mathrm{MEFs}$ $(\mathrm{EV} 1+\mathrm{EV} 2)$ showed an apoptotic response to etoposide, but not to IR. Reconstitution of Bid enhanced etoposide-induced apoptosis and enabled IR-induced apoptosis (Figure 1b). The p53-deficient $\mathrm{Bid}^{-/-} \mathrm{MEFs}$ (p53 RNAi + EV2) did not show an apoptotic response to either etoposide or IR, while Bid reconstitution enabled this response (Figure 1c). These data clearly indicate a role for Bid in the apoptotic response to these DNA-damaging stimuli in SV40-transformed MEFs. These cells require Bid 

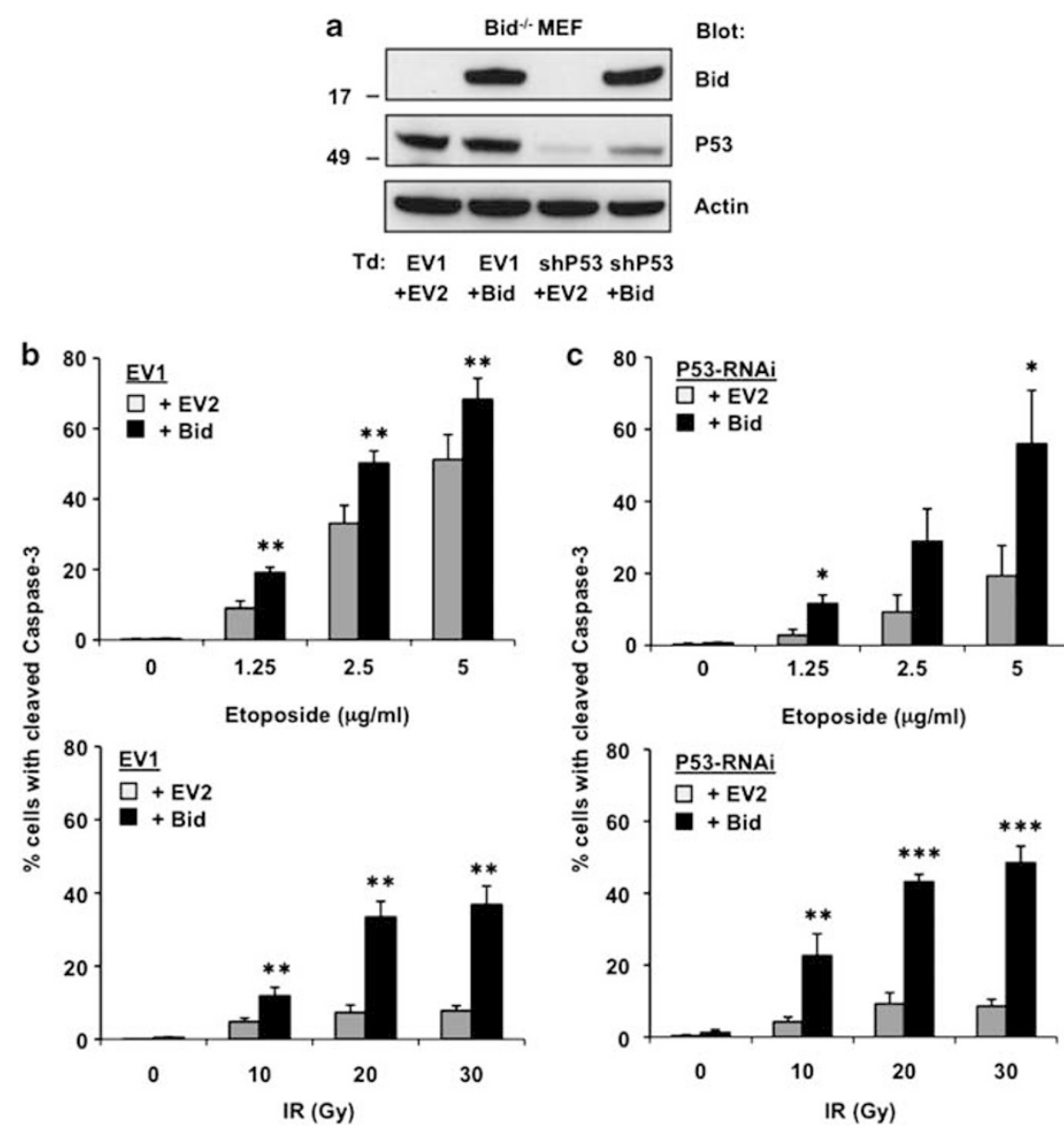

Figure 1 The p53 status can influence the reliance on Bid for etoposide- and IR-induced apoptosis. SV40-transformed Bid ${ }^{-/-}$MEFs were retrovirally transduced (Td) with an empty RNAi vector (EV1) or with p53 shRNA, together with an empty expression vector (EV2) or a vector encoding WT Bid. (a) Validation of p53 downregulation by p53 shRNA and Bid expression from the introduced vector in the relevant MEF cell lines, as demonstrated by immunoblotting with antibodies to p53 and Bid on total cell lysates. Immunoblotting for actin served as a loading control (b, c) Sensitivity of control (EV1-transduced) MEFs (b) and p53-deficient (p53-RNAi) MEFs (c) to apoptosis induction by DNA-damaging regimens. Cells were exposed to the indicated dosages of etoposide or IR. Apoptosis levels were determined as the percentage of cells with cleaved caspase-3 after $24 \mathrm{~h}$ (etoposide) or $48 \mathrm{~h}$ (IR). Data presented are expressed as means of three independent experiments \pm s.d. Statistically significant differences between values of EV and Bid samples are indicated for $* P<0.05, * * P<0.01$ and $* * * P<0.001$.

for IR-induced apoptosis regardless of their p53 status and they require Bid for etoposide-induced apoptosis when p53 cannot participate in the response. We conclude that Bid can convey the apoptotic response to etoposide and IR in a p53-independent manner. Moreover, the p53 status of transformed cells can determine the extent of their reliance on Bid for the apoptotic response to these stimuli.

\section{Bid can contribute to clonogenic cell death in response to etoposide and IR}

For tumor therapy, the relevant parameter is the clonogenic potential of the tumor cells after treatment. To investigate the importance of Bid-dependent apoptosis in arresting the clonogenicity of transformed cells with DNA-damaging stimuli, we performed clonogenic survival assays. The p53-RNAi $\mathrm{Bid}^{-/-} \mathrm{MEF}$ cell lines expressing Bid or empty control vector (EV) were exposed to different doses of etoposide or IR and surviving colonies were quantified. The presence of Bid in p53-deficient MEFs reduced clonogenic survival upon etoposide (Figure 2a) or IR treatment (Figure 2b). This demonstrated that in these p53-deficient, SV40-transformed cells, Bid is important for clonogenic cell death following treatment with DNA-damaging anti-cancer regimens.

The nature of cell transformation determines whether Bid mediates a pro-apoptotic response to etoposide or $I R$

The discussion regarding the existence of a Bid-dependent apoptotic response to DNA damage focused in part on the cellular background of the WT and $\mathrm{Bid}^{-/}$ cells that were compared. However, in our Bid reconstitution set-up, such variables were excluded. Another variable might be the nature of cell transformation. Kamer et al. (2005) primarily studied hTERT-immortalized $\mathrm{Bid}^{-/-}$ MEFs that were reconstituted with Bid and found Bid to 

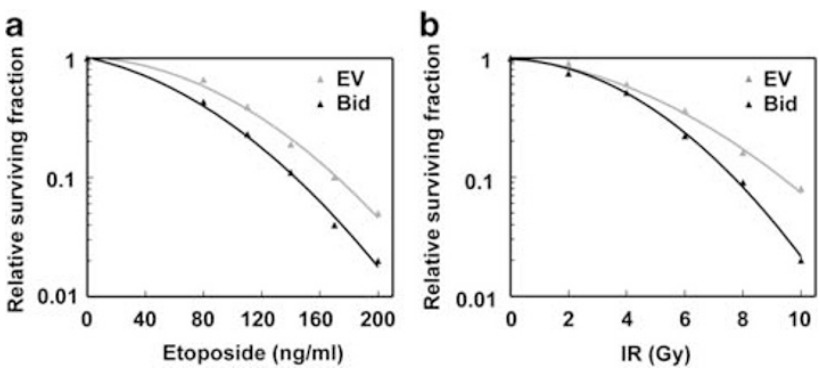

Figure 2 Bid can contribute to clonogenic cell death in response to etoposide and IR. (a, b) P53-RNAi Bid ${ }^{-1-}$ MEFs carrying an empty vector (EV) or stably expressing WT Bid were exposed to the indicated dosages of etoposide (a) or IR (b). Surviving colonies were counted 14 days post-treatment. The relative surviving fraction is plotted against the dose of etoposide or IR. Data presented are representative of two independent experiments.

have an important role in etoposide- and IR-induced apoptosis. Kaufmann et al. (2007), however, compared various $\mathrm{E} 1 \mathrm{~A} / \mathrm{Ras}$-transformed $\mathrm{WT}$ and $\mathrm{Bid}^{-/-} \mathrm{MEF}$ lines and found no evidence for a contribution of Bid to these apoptotic responses.

Therefore, to gain further insight, we tested E1A/ Ras-transformed $\mathrm{Bid}^{-/-}$MEF lines for their response to etoposide and IR, before and after Bid reconstitution and in the presence or absence of p53. Four different cell lines were created, exactly as outlined for SV40-transformed MEFs. Bid reconstitution and p53 downregulation were validated by immunoblotting (Supplementary Figure 2a). The cell lines were exposed to various doses of etoposide and IR. Downregulation of p53, although not complete (Supplementary Figure 2a), reduced the apoptosis sensitivity of the cells to both stimuli (Supplementary Figure 2b). However, Bid reconstitution did not alter the apoptosis sensitivity of these E1A/Ras-transformed cells to etoposide or IR, either in the p53-proficient or in the p53-deficient situation (Supplementary Figure 2b). Our approach excluded cellular background differences and confirmed that Bid does not contribute to the apoptotic response to etoposide or IR in E1A/Ras-transformed MEFs. Moreover, p53 downregulation did not make the Biddependent pathway more prevalent.

\section{Bid requires its BH3 domain to indirectly activate Bak/ Bax during DNA-damage-induced apoptosis}

The conventional pro-apoptotic function of $\mathrm{BH} 3-$ only proteins lies in their $\alpha$-helical BH3 domain, which can interact with the $\mathrm{BH} 1 / \mathrm{BH} 2$ groove of other family members (Letai et al., 2002). To study whether Bid mediated DNA-damage-induced apoptosis by virtue of its $\mathrm{BH} 3$ domain, we generated a Bid variant with glycine 94 in its BH3 domain mutated into a glutamate (Bid G94E). It was previously shown that the tBid-C (C-terminal fragment of Bid) with a G94E mutation could not efficiently interact with Bak/Bax or the antiapoptotic Bcl-2 proteins and displayed reduced proapoptoptic activity (Willis et al., 2007). SV40-transformed p53 RNAi $\mathrm{Bid}^{-1-}$ MEF cells were stably transduced to express either WT Bid or Bid G94E (Figure 3a). The effect of the G94E mutation on Bid function was tested by its impact on death receptor-induced apoptosis. Cells were treated with different doses of tumor necrosis factoralpha $(\mathrm{TNF} \alpha)$ in combination with cycloheximide (to inhibit NF- $\kappa \mathrm{B}$ activation) and apoptosis was read out as before. $\mathrm{TNF} \alpha$-induced apoptosis was significantly lower in cells expressing the Bid G94E mutant than in cells expressing WT Bid, thus validating the construct (Figure 3b). The Bid G94E mutant was also significantly less effective than WT Bid in inducing apoptosis after treatment with etoposide or IR (Figure 3b), indicating that $\mathrm{Bid}$ required a functional $\mathrm{BH} 3$ domain to mediate apoptosis in response to these stimuli.

In the indirect model for $\mathrm{Bax} / \mathrm{Bak}$ activation, inhibitory Bcl-2 family members bind and sequester $\mathrm{Bax} / \mathrm{Bak}$, thus preventing them from multimerizing and causing MOMP. BH3-only proteins displace $\mathrm{Bax} / \mathrm{Bak}$ from this complex by binding to inhibitory Bcl-2 family members with their BH3 domain (Willis et al., 2007). In the direct activation model, Bid activates Bax and/or Bak by a direct physical interaction using its $\mathrm{BH} 3$ domain (Letai et al., 2002). A tBid-C mutant with glycine 94 replaced by an alanine (G94A) cannot bind to Bax and Bak but binds all anti-apoptotic Bcl-2 proteins (Willis et al., 2007). To test whether Bid acted in the DNA damage pathway by direct or indirect Bax/Bak activation, SV40-transformed p53-RNAi $\mathrm{Bid}^{-/-} \mathrm{MEFs}$ were reconstituted with WT Bid or G94A Bid (Figure 3c) and their apoptotic response to DNA-damage-induced apoptosis was examined. The Bid G94A mutant was as effective as WT Bid in mediating etoposide- or IRinduced apoptosis (Figure 3d). We conclude from these findings that in p53-deficient SV40-transformed MEFs, Bid mediates apoptosis in response to etoposide and IR by virtue of its $\mathrm{BH} 3$ domain and does not directly activate $\mathrm{Bax} / \mathrm{Bak}$, but most likely relieves them from inhibition by anti-apoptotic Bcl-2 proteins.

\section{Bid-dependent DNA-damage-induced apoptosis proceeds via the mitochondrial pathway}

To evaluate whether Bid-dependent DNA-damageinduced apoptosis proceeded via the mitochondrial pathway, we overexpressed $\mathrm{Bcl}-2$ in Bid-expressing SV40-transformed p53-RNAi $\mathrm{Bid}^{-/-}$MEFs (Figure 4a) and tested the effect on etoposide- and IR-induced apoptosis. Bcl-2 overexpression significantly inhibited both etoposide- and IR-induced apoptosis (Figure 4b). This further supports that Bid acts in this pathway by virtue of $\mathrm{BH} 3$-domain-dependent interactions with its family members. It also strongly suggests that Biddependent DNA-damage-induced apoptosis required MOMP. Because Bcl-2 may also regulate the permeability of the endoplasmic reticulum membrane (Lam et al., 1994), the inhibitory effect of Bcl-2 did not unambiguously implicate the mitochondria in DNA-damage-induced apoptosis. Therefore, we overexpressed dominant-negative caspase-9 (dnCaspase-9; Figure 4c), which abrogates apoptosome-mediated caspase-9 activation. dnCaspase-9 significantly blocked 

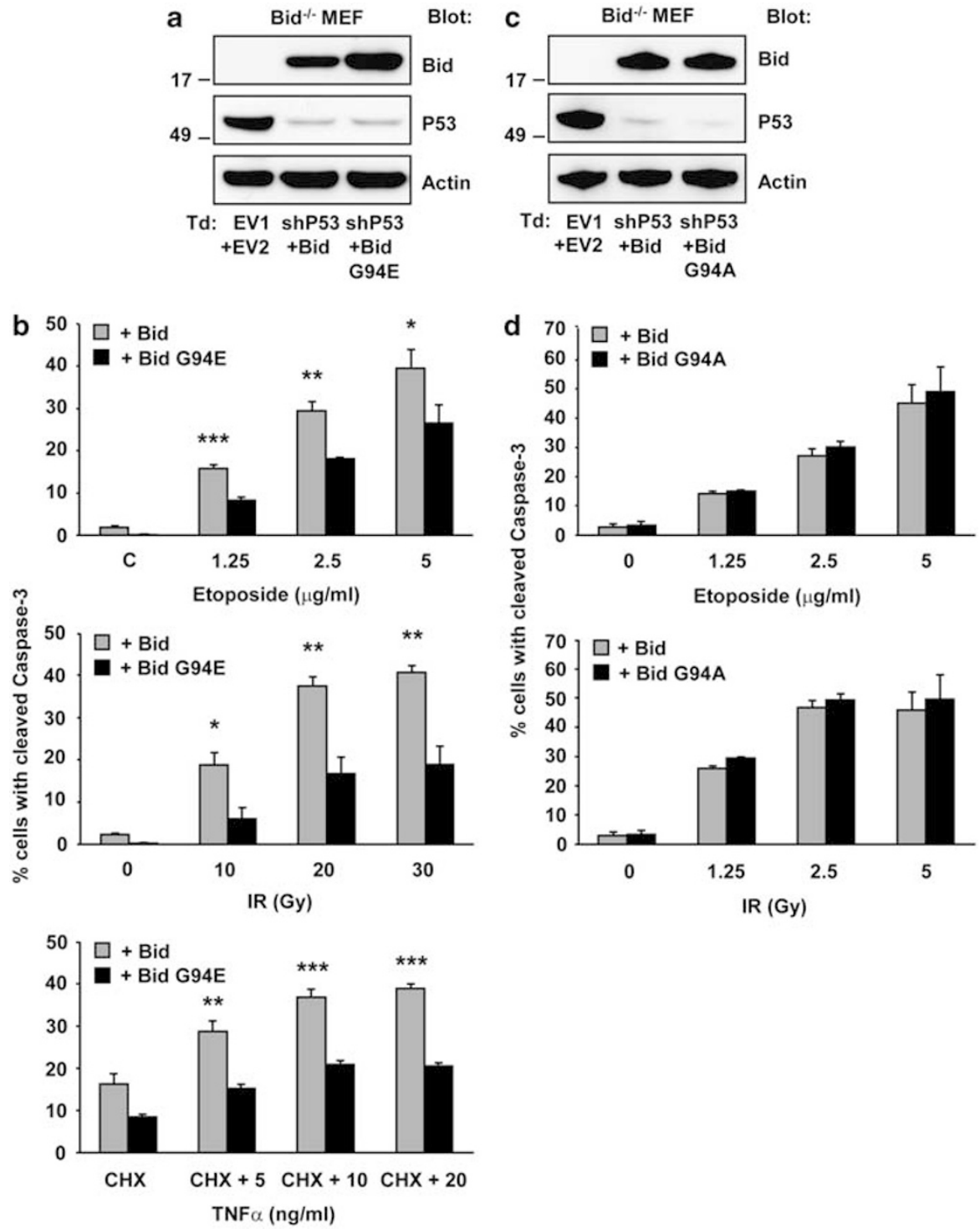

Figure 3 Bid uses its BH3 domain to indirectly activate Bax and/or Bak during etoposide- and IR-induced apoptosis. p53-RNAi $\mathrm{Bid}^{-/-}$MEFs were transduced (Td) to stably express WT Bid, the Bid G94E mutant or the Bid G94A mutant. (a, c) Downregulation of p53 by RNAi and Bid protein expression from the introduced vectors were validated by immunoblotting, where actin served as a loading control. (b) p53-RNAi Bid ${ }^{-/-}$MEFs expressing WT Bid or Bid G94E were exposed to the indicated dosages of etoposide or IR, or to TNF $\alpha$ in combination with cycloheximide (CHX) as a validation of the Bid G94E mutant. Apoptosis levels were determined as the percentage of cells with cleaved caspase- 3 after $24 \mathrm{~h}$ (etoposide), $48 \mathrm{~h}$ (IR) or $5 \mathrm{~h}$ (TNF $\alpha+\mathrm{CHX}$ ). Background apoptosis levels, as those observed in p53-RNAi $\mathrm{Bid}^{-/-}$MEF carrying EV2, were subtracted from obtained values for all stimuli. (d) p53-RNAi Bid ${ }^{-/-}$ MEFs expressing WT Bid or Bid G94A were exposed to the indicated dosages of etoposide or IR and apoptosis was read out as outlined in (b). Data in (b) and (d) are expressed as means of three independent experiments \pm s.d. Statistically significant differences between values of WT Bid and Bid G94E are indicated in (b) for ${ }^{*} P<0.05$, ${ }^{* *} P<0.01$ and ${ }^{* * *} P<0.001$.

both etoposide- and IR-induced apoptosis (Figure 4d). Together, these observations demonstrate that Biddependent DNA-damage-induced apoptosis proceeds via the mitochondrial pathway for caspase activation.

\section{Bid activation by DNA-damaging stimuli does not require} cleavage at aspartates 55, 60 and/or 75

Bid is an auto-inhibitory molecule that has-in the fulllength inactive state - its pro-apoptotic BH3 domain sequestered by residues in its $\mathrm{N}$-terminal region (see
Supplementary Figure 3 for Bid structure; Chou et al., 1999; McDonnell et al., 1999; Tan et al., 1999). Proteolytic cleavage of Bid in its unstructured loop triggers mitochondrial translocation (Gross et al., 1999) and proteasomal degradation of Bid's N-terminal fragment, allowing tBid-C to perform its pro-apoptotic function (Tait et al., 2007). In the death receptor pathway, Bid is cleaved at aspartate 60 (D60) by caspase-8 (Luo et al., 1998). Caspase-2 and -3 can also cleave Bid at D60 (Gross et al., 1999; Guo et al., 2002), whereas Granzyme B cleaves Bid at aspartate 75 (D75; Luo et al., 1998). 

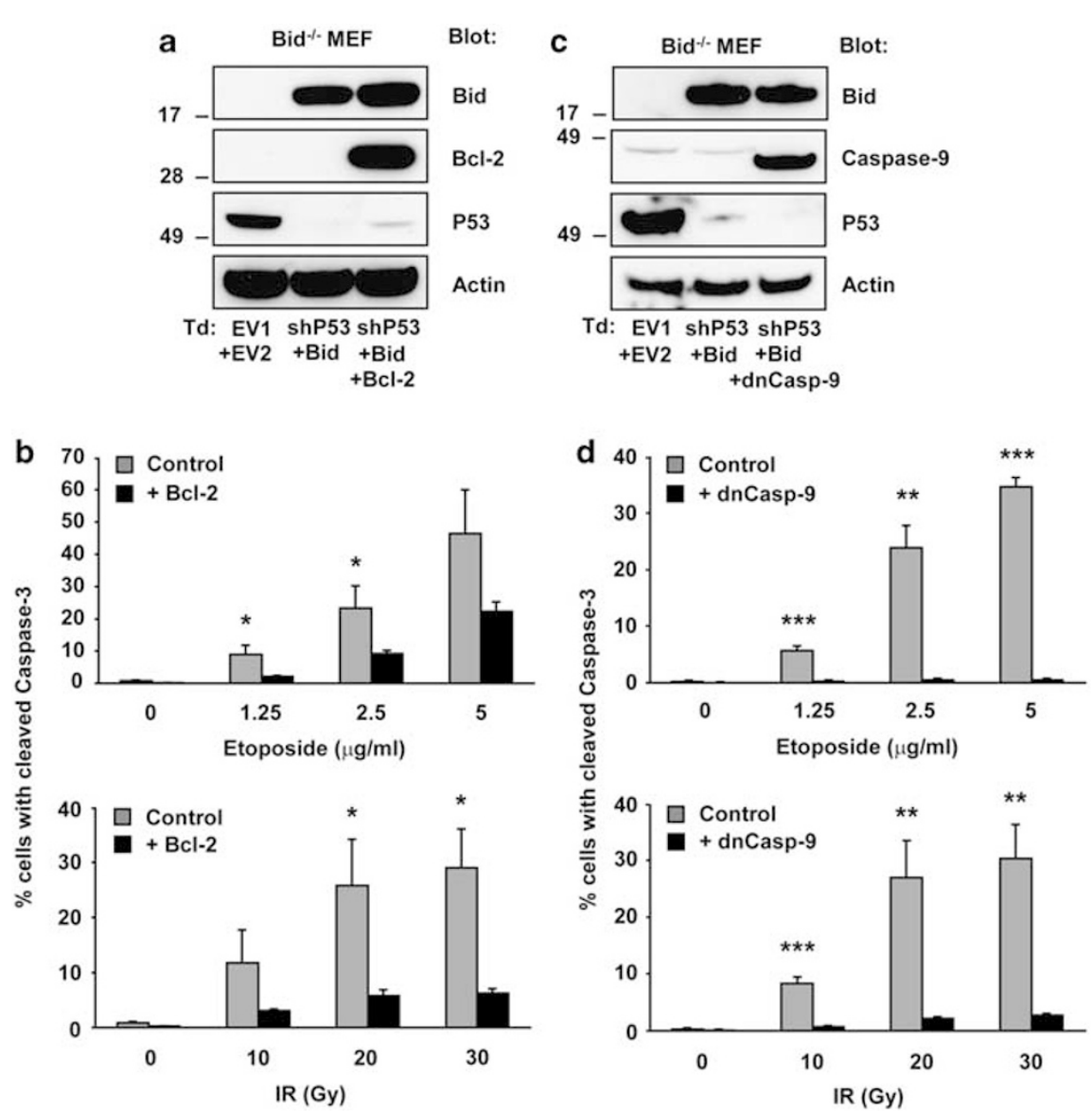

Figure 4 Bid-dependent apoptosis in response to etoposide and IR proceeds via the mitochondria. p53-RNAi Bid ${ }^{-/}$MEFs that had been transduced to stably express WT Bid were used as such (control) or additionally transduced (Td) to express Bcl-2 or dnCasp-9. (a, c) Downregulation of $\mathrm{p} 53$ by RNAi and expression of Bid, Bcl-2 or dnCasp-9 protein from the introduced vectors were validated by immunoblotting on total cell lysates, where actin served as a loading control. (b) Control or Bcl-2-expressing cells were exposed to the indicated dosages of etoposide or IR. Apoptosis levels were determined as the percentage of cells with cleaved caspase- 3 after $24 \mathrm{~h}$ (etoposide) or $48 \mathrm{~h}$ (IR). (d) Control or dnCasp-9-expressing cells were exposed to the indicated dosages of etoposide or IR and apoptosis was read out as indicated for panel (b). Data presented in (b) and (d) are expressed as means of three independent experiments \pm s.d. Statistically significant differences between values of control and Bcl-2 or dnCasp-9 samples are indicated for $* P<0.05,{ }^{* *} P<0.01$ and ${ }^{* * *} P<0.001$.

Biochemical analysis after treatment of Bid-reconstituted MEF cells with etoposide or IR did not reveal Bid cleavage as assessed in total cell lysates (Supplementary Figure 4 and data not shown). This was not surprising because in our experience only minute amounts of Bid cleavage products are produced in response to these stimuli, which we could only demonstrate biochemically in purified mitochondrial fractions after biosynthetic labeling (Werner et al., 2004 and results not shown). Moreover, because Bid can be cleaved by effector caspases in a feed-forward loop for MOMP (Slee et al., 2000), analysis for the Bid cleavage that is instrumental in initial MOMP induction should be done in cells in which the feed-forward loop is excluded, such as by expression of dnCaspase-9. Also, under those conditions, we could not conclusively detect Bid cleavage products after treatment with etoposide or IR either in total cell lysates or after immunoprecipitation (results not shown). For these reasons and to assess the functional relevance of a possible Bid cleavage, we decided to use a genetic approach. We first tested whether D60 or D75 were essential in p53-deficient MEFs for the responses to etoposide and IR. SV40-transformed p53-RNAi $\mathrm{Bid}^{-1-}$ MEFs cells were stably reconstituted with D60E or D75E single-point mutants, or a D60E/ D75E double-point mutant of Bid. Cells reconstituted with WT Bid served as control (Figure 5a). Death receptor stimulation by $\mathrm{TNF} \alpha$ was used to validate the Bid mutants. In contrast to WT Bid, the Bid D60E mutant could not mediate TNF $\alpha$-induced apoptosis. Bid D75E mutation did not significantly impede its capacity to relay the apoptotic signal (Figure 5b). This indicates that D60 is the predominant cleavage site for Bid activation in death-receptor-induced apoptosis. Bid D60E/ $\mathrm{D} 75 \mathrm{E}$ mutation prevented $\mathrm{TNF} \alpha$-induced apoptosis as effectively as the Bid D60E mutation (Figure 5c). Next, we studied the relevance of Bid cleavage at D60 and/or D75 for DNA-damage-induced apoptosis. Single D60E or D75E mutation did not affect etoposide or IR-induced apoptosis (Figure 5b); combined D60E/D75E mutation 


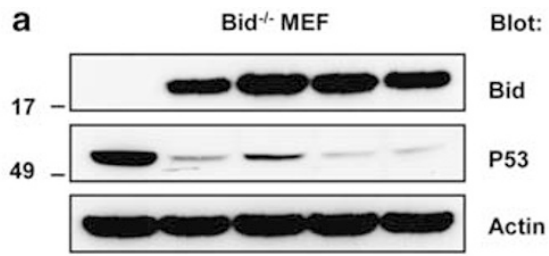

Td: EV1 shP53 shP53 shP53 shP53 + EV2 +Bid +Bid +Bid +Bid D60E D75E D60E/
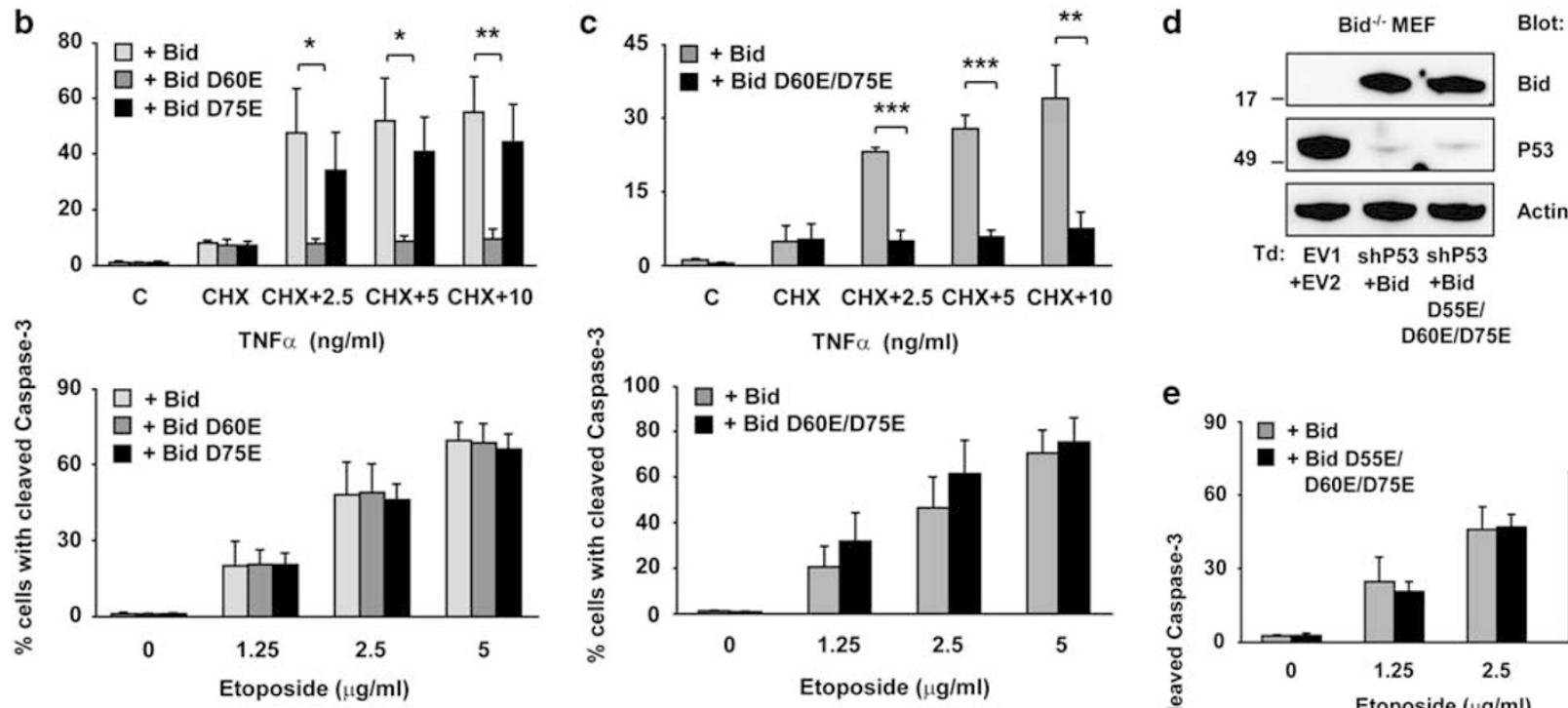

e
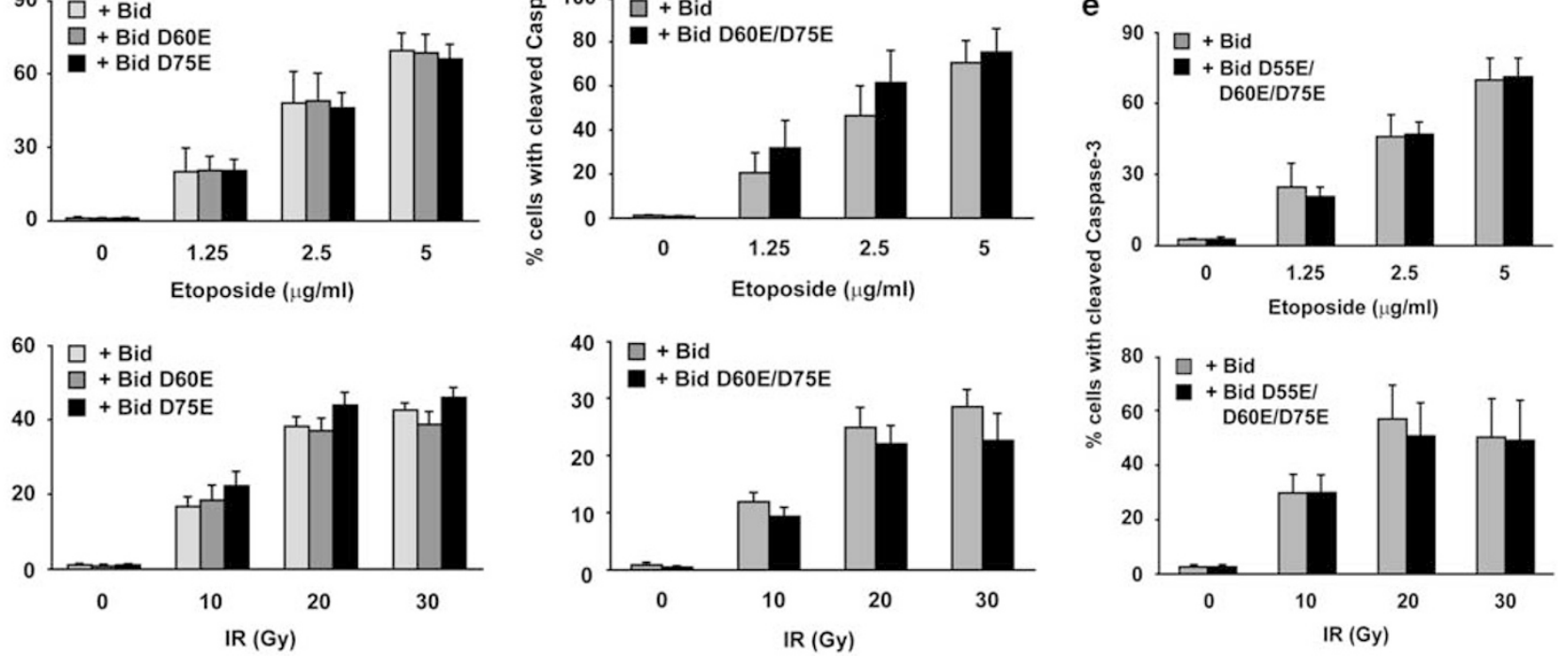

Figure 5 Bid cleavage at aspartate residues in its unstructured loop is not required for apoptosis induction in response to etoposide and IR. p53-RNAi Bid ${ }^{-1}$ MEFs were transduced (Td) to stably express WT Bid, or the Bid mutants Bid D60E, Bid D75E, Bid D60E/ D75E or Bid D55E/D60E/D75E. (a, d) Downregulation of p53 by RNAi and expression of WT or mutant Bid protein from the introduced vectors were validated by immunoblotting on total cell lysates, where actin served as a loading control. (b) p53-RNAi Bid ${ }^{-1-}$ MEFs expressing WT Bid, Bid D60E or Bid D75E were exposed to the indicated dosages of TNF $\alpha+$ cycloheximide (CHX), etoposide or IR. Apoptosis levels were determined as the percentage of cells with cleaved caspase-3 after $5 \mathrm{~h}(\mathrm{TNF} \alpha+\mathrm{CHX}), 24 \mathrm{~h}$ (etoposide) or $48 \mathrm{~h}$ (IR). (c) P53-RNAi Bid ${ }^{-/-}$MEFs expressing WT Bid or Bid D60E/D75E were exposed to the indicated dosages of TNF $\alpha+\mathrm{CHX}$, etoposide or IR and apoptosis was read out as outlined for panel (b). (e) P53-RNAi Bid ${ }^{-/}$MEFs expressing WT Bid or Bid D55E/ D60E/D75E were exposed to the indicated dosages of etoposide or IR and apoptosis was read out as outlined for panel (b). Data presented in (b), (c) and (e) are expressed as means of three independent experiments \pm s.d. Statistically significant differences between values of Bid and Bid D60E or D60E/D75E samples are indicated for $* P<0.05, * * P<0.01$ and $* * * P<0.001$.

also had no effect (Figure 5c). Potentially, Bid can also be cleaved at aspartate 55 (D55) by caspase-3, as revealed by analysis with the Merops peptidase database (http://merops.sanger.ac.uk). We therefore expressed a Bid D55E/D60E/D75E mutant in SV40-transformed p53-RNAi Bid ${ }^{-/}$MEFs (Figure 5d). This Bid mutant relayed the apoptotic signal as effectively as WT Bid (Figure 5e). Together, these data indicate that Bid does not require cleavage at any of the available aspartate residues in its unstructured loop to induce apoptosis in response to the DNA-damaging stimuli. These data also excluded that Bid made its contribution to apoptotic execution in a feed-forward loop for MOMP, after cleavage by caspases downstream of the mitochondria.

Bid activation by DNA-damaging stimuli does not require cleavage at other known protease recognition sites In vitro studies have shown that Bid can also be activated through proteolytic cleavage by calpain or different 

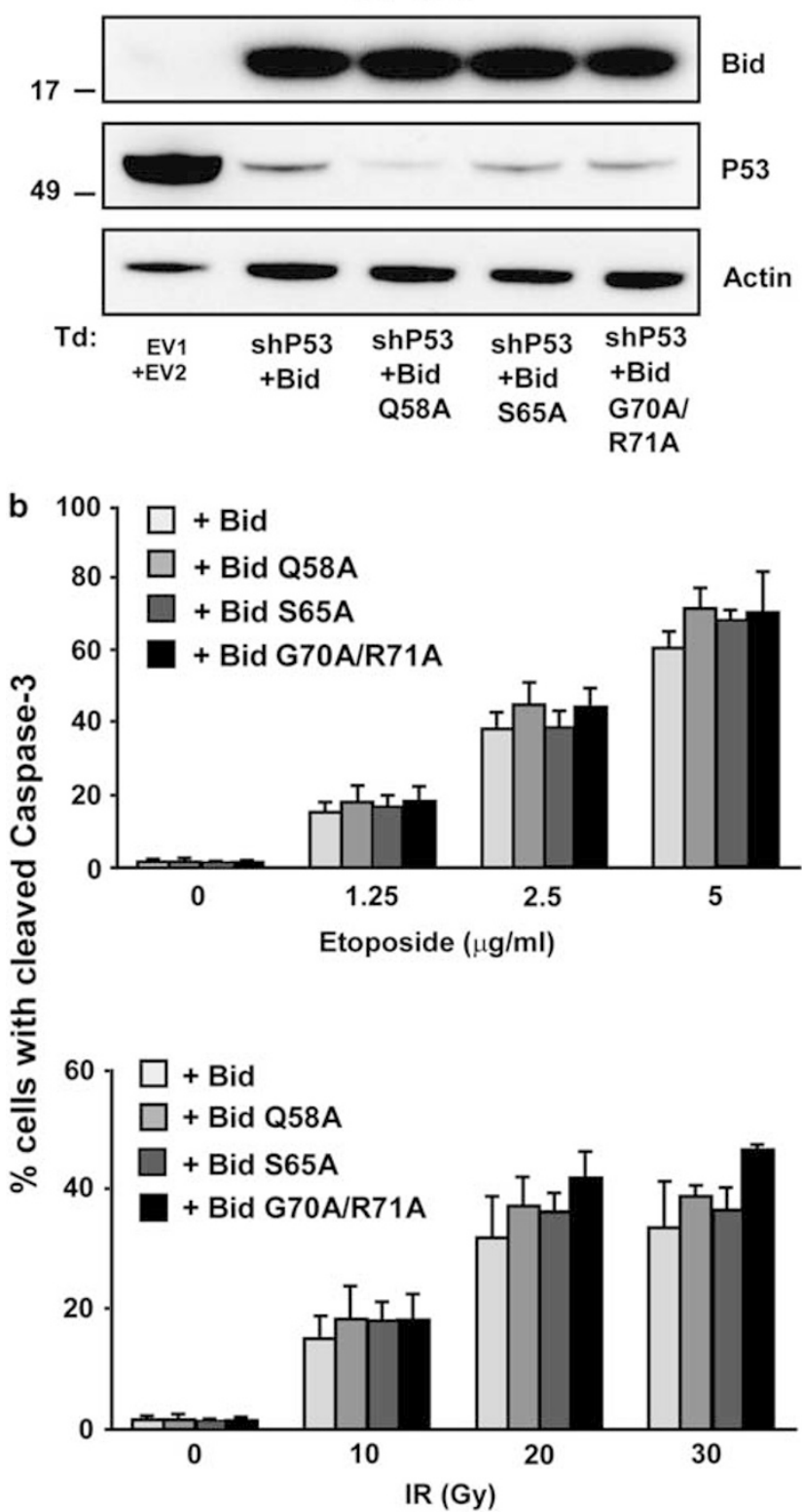

Figure 6 Bid cleavage at alternative defined proteolytic cleavage sites in its unstructured loop is not required for apoptosis induction in response to etoposide and IR. p53-RNAi $\mathrm{Bid}^{-/-}$MEFs were transduced (Td) to stably express WT Bid, or the Bid Q58A, Bid S65A or Bid G70A/R71A mutants. (a) Downregulation of p53 by RNAi and expression of WT or mutant Bid protein from the introduced vectors were validated by immunoblotting on total cell lysates, where actin served as a loading control. (b) p53-RNAi $\mathrm{Bid}^{-1-}$ MEFs expressing WT Bid, Bid Q58A, Bid S65A or Bid G70A/R71A were exposed to the indicated dosages of etoposide or IR. After $24 \mathrm{~h}$ (etoposide) or $48 \mathrm{~h}$ (IR), apoptosis levels were determined as the percentage of cells with cleaved caspase-3. Data are expressed as means of three independent experiments \pm s.d.

cathepsins within its unstructured loop (Mandic et al., 2002; Cirman et al., 2004). Calpain cleavage site glycine 70 (G70) and cathepsin cleavage sites glutamine 58 (Q58), serine 65 (S65) and arginine 71 (R71) are highly conserved between species. To investigate whether Bid cleavage at one of these residues was required for
DNA-damage-induced apoptosis in SV40-transformed p53-deficient MEFs, we expressed WT Bid or Bid Q58A, S65A and G70A/R71A mutants in p53-RNAi Bid ${ }^{-1-}$ MEFs (Figure 6a) and tested their effects on DNAdamage-induced apoptosis. All mutants were as capable as WT Bid to relay the apoptotic signal in response to etoposide and IR (Figure 6b). We conclude that Bid does not require proteolysis at defined calpain or cathepsin cleavage sites in its unstructured loop to induce apoptosis in response to the DNA-damaging stimuli.

Bid activation by DNA-damaging stimuli does not involve cleavage within its unstructured loop

Together, our results so far indicate that activation of Bid during DNA-damage-induced apoptosis does not require proteolysis at a conventional cleavage site within its unstructured loop. To study whether another cleavage site within its unstructured loop might be required for Bid activation, we generated a Bid mutant (Bid w/o loop) with its 37-amino-acid unstructured loop replaced by a short, random stretch of glycines and serines. All potential cleavage sites present in the unstructured loop were thereby removed. The SV40transformed p53-RNAi $\mathrm{Bid}^{-/-}$MEFs were reconstituted with the Bid w/o loop mutant or WT Bid as a control (Figure 7a). In contrast to WT Bid, the Bid w/o loop mutant could not mediate $\mathrm{TNF} \alpha$-induced apoptosis at all, thus validating the construct (Figure 7b). However, the Bid w/o loop mutant was as effective as WT Bid in mediating etoposide- or IR-induced apoptosis (Figure $7 \mathrm{~b}$ ). These data prove that Bid activation during DNA-damage-induced apoptosis does not involve cleavage within its unstructured loop.

\section{Discussion}

In accord with certain previous works, we demonstrate that Bid can convey the apoptotic signal in response to IR or etoposide, but its participation depends on the cellular background. Participation of BH3-only proteins in the response to apoptotic stimuli is highly cell typeand stimulus-dependent. In the mouse, Puma and - to a lesser extent-Noxa are required for the apoptotic response to DNA damage in primary thymocytes, mature $\mathrm{T}$ cells, intestinal epithelial cells and neuronal cells (Michalak et al., 2008). In mature B cells, BH3-only protein Bim was also important and in pre-B cells, combined deletion of the puma and noxa genes did not reproduce the effect of $\mathrm{p} 53$ deletion, indicating that other BH3-only proteins had a role (Erlacher et al., 2005; Michalak et al., 2008). Testing a potential role for Bid, Kaufmann et al. (2007) found normal apoptotic responses to IR and etoposide in $\mathrm{Bid}^{-/-}$thymocytes, pre$\mathrm{B}$ cells, resting mature $\mathrm{T}-$ and $\mathrm{B}$ cells, and proliferating $\mathrm{T}$ cells. These findings are not in conflict with those of Kamer et al. (2005) and Zinkel et al. (2005), and emphasize that in these healthy lymphoid cells, Bid is not important for this response. In mouse brain tissue, 
however, Bid complemented Bim and Puma in apoptosis induction after IR and the three proteins were collectively responsible for complete apoptotic execution.
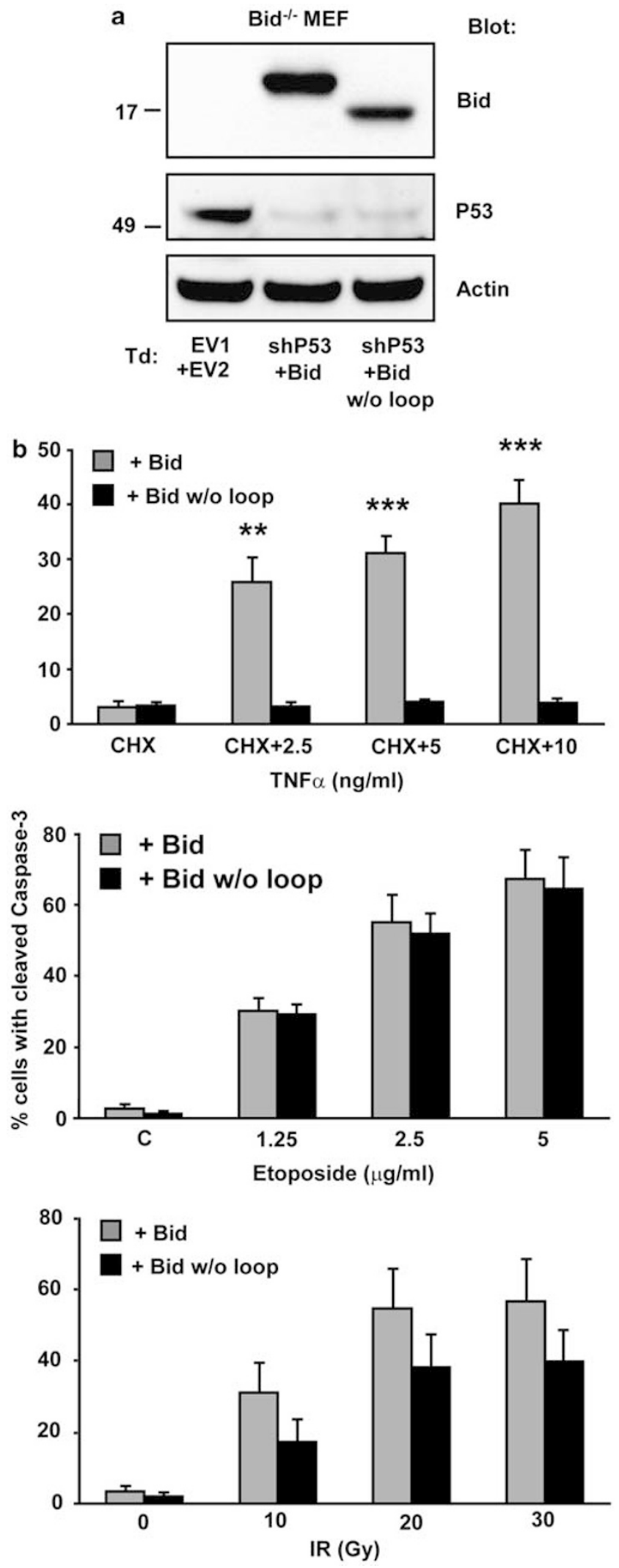

In fact, the phenotype of mice with triple deletion of the bid, bim and puma genes suggested that these three proteins are collectively responsible for Bax and Bak activation in response to diverse stimuli in multiple tissues (Ren et al., 2010).

Kamer et al. (2005) demonstrated by Bid reconstitution that in hTERT-immortalized MEFs, Bid mediated the apoptotic response to IR and etoposide. We have received hTERT-immortalized $\mathrm{Bid}^{-1-} \mathrm{MEFs}$ from this research group and independently confirmed this finding (results not shown). We report here that also in SV40transformed MEFs, Bid conveys the apoptotic response to IR and etoposide. Bid most evidently contributed to the etoposide response when p53 was downregulated, but the IR response strongly relied on $\mathrm{Bid}$, both in the presence and in the absence of p53. In E1A/Rastransformed MEFs, however, Bid did not contribute to the apoptotic response to IR or etoposide, when p53 was either expressed or downregulated. We have hereby extended the study of Kaufmann et al. (2007), who compared various WT and $\mathrm{Bid}^{-/-} \mathrm{E} 1 \mathrm{~A} / \mathrm{Ras}$-transformed MEF cell lines, but did not perform reconstitution experiments or test the effect of p53 downregulation. We conclude that it is not the p53 status per se, but the oncogenic pathways that are active in the MEF cell lines, in combination with the p53 status, that determine their dependence on Bid for apoptosis induction by IR and etoposide.

Bid was reconstituted in its full-length, inactive form, in which it is expressed constitutively in many normal and tumor cell types (Krajewska et al., 2002). We showed that Bid reconstitution did not alter the expression level of various pro- and anti-apoptotic Bcl-2 family proteins (Supplementary Figure 1). Also, Bid reconstitution did not alter the apoptosis sensitivity of transformed MEFs indirectly, because it did not influence the response of E1A/Ras-transformed MEFs to etoposide or IR at all. This is in agreement with the fact that Bid needs to be activated to perform its proapoptotic function. We found that in SV40-transformed MEFs, Bid's role in apoptosis induction in response to etoposide and IR was conventional, in the sense that it needed an intact $\mathrm{BH} 3$ domain, indirectly activated Bax and/or Bak, and relied on MOMP and caspase- 9 to activate effector capases. Bid activation did not involve

Figure 7 Bid cleavage in its unstructured loop is not required for apoptosis induction in response to etoposide and IR. p53-RNA $\mathrm{Bid}^{-/-}$MEFs were transduced (Td) to stably express WT Bid or Bid with the unstructured loop exchanged for a random stretch of Gly and Ser amino acids (Bid w/o loop). (a) Downregulation of p53 by RNAi and expression of WT or mutant Bid protein from the introduced vectors were validated by immunoblotting on total cell lysates, where actin served as a loading control. (b) p53-RNAi $\mathrm{Bid}^{-1-}$ MEFs expressing WT Bid or the Bid w/o loop mutant were exposed to the indicated dosages of TNF $\alpha+$ cycloheximide (CHX), etoposide or IR. After $5 \mathrm{~h}$ (TNF $\alpha+\mathrm{CHX}), 24 \mathrm{~h}$ (etoposide) or $48 \mathrm{~h}$ (IR), apoptosis levels were determined as the percentage of cells with cleaved caspase-3. Data are expressed as means of three independent experiments \pm s.d. Statistically significant differences between values of $\mathrm{Bid}$ and $\mathrm{Bid} \mathrm{w} / \mathrm{O}$ loop are indicated for $* * P<0.01$ and $* * * P<0.001$ 
cleavage at defined caspase cleavage sites. Accordingly, the D59 caspase cleavage site in mouse Bid was found to be irrelevant for its supporting role in apoptosis induction by etoposide in primary MEFs (Sarig et al., 2003). Bid can also participate in the apoptotic response to DNA-damaging anti-cancer regimens in human tumor cells. In p53 mutant Jurkat T-acute lymphoblastic leukemia cells, Bid depletion experiments indicated that Bid conveyed the apoptotic response to IR and etoposide. In this response, Bid can act downstream of the apoptosome in an amplification loop for mitochondrial activation (Shelton et al., 2009). However, by expression of dominant-negative caspases and RNAi, we showed that Bid also acted upstream of the apoptosome in a caspase-independent manner (Werner et al., 2004). In HeLa cervix carcinoma cells, which have a dysfunctional p53 pathway due to human papillomavirus-encoded E6 and E7 proteins, Bid downregulation by RNAi was found to decrease etoposide-, doxorubicin- and oxaliplatin-induced apoptosis. RNAi for Puma showed that Bid acted in concert with Puma in execution of the apoptotic response to oxaliplatin (Koehler et al., 2008). Furthermore, in the response to oxaliplatin, Bid cleavage at D59 was not required for apoptosis induction (Anguissola et al., 2009). These data agree that Bid can be activated in response to DNA damage in a caspase-independent manner. We now show that in SV40-transformed MEFs, defined cleavage sites for calpains or cathepsins also did not have a role in Bid activation. Moreover, even complete removal of the unstructured loop did not affect the pro-apoptotic response of Bid to IR or etoposide.

Although it is difficult to rule out Bid activation by cleavage outside its unstructured loop, the combined data suggest that it might be full-length Bid that induces apoptosis in response to the dsDNA break inducers etoposide and IR in the MEFs examined here. In the case of oxaliplatin stimulation of HeLa cells, a Bid-FRET probe indicated that full-length Bid translocated to the mitochondria in a caspase- and calpain-independent manner. We have also examined Bid translocation in the context of our study, but found the data difficult to quantify, because the different cells within a population responded to IR or etoposide in an asynchronous manner over the protracted period of $8-24 \mathrm{~h}$ after the initial stimulation that was analyzed. It was also not possible to determine whether mitochondrial association of Bid was the cause or consequence of apoptosis induction or induction of mitochondrial permeability (in case of cells expressing dnCaspase-9). Full-length Bid has previously been implicated in anoikis and glutamate-induced apoptosis in neurons (Valentijn and Gilmore, 2004; Ward et al., 2006). Also, it has been found that full-length Bid can be transported to the mitochondria, with the help of PACS-2 (Simmen et al., 2005). It has been proposed that Bid is activated in the nucleus to mediate DNA-damageinduced apoptosis, on the basis of several observations. First, full-length Bid was seen to translocate from the cytosol to the nucleus and from the nucleus to the cytosol in response to DNA-damaging anti-cancer drugs in HeLa cells (Oberkovitz et al., 2007; Anguissola et al.,
2009). In addition, enforced nuclear retention of Bid through fusion of Bid with a nuclear localization signal inhibited etoposide-induced apoptosis (Oberkovitz et al., 2007). Thus, DNA damage may activate full-length Bid to translocate from the nucleus to the mitochondria and induce MOMP. What might trigger this presumed re-localization is not known. The Bid phosphorylation that occurs in response to dsDNA break inducers is not required for its role in apoptosis induction (Kamer et al., 2005). Because full-length Bid is auto-inhibited, it must be activated to expose its BH3 domain (Tait et al., 2007). How this can occur when Bid is not cleaved in its unstructured loop is unclear. Potentially, post-translational modification can induce a conformational change that enables Bid to expose its $\mathrm{BH} 3$ domain and participate in apoptosis. This modification must occur outside the loop, as its removal did not affect Bid activity.

As a potential mediator of DNA-damage-induced apoptosis, Bid might function as a tumor suppressor. Zinkel et al. (2005) postulated such a role for Bid, which was supported by their previous finding that $\mathrm{Bid}^{-/-}$mice were at the risk of developing a fatal myeloproliferative disorder upon aging (Zinkel et al., 2003). This has also been debated, but further work will have to point out whether loss of Bid can collaborate with oncogenic mutations to promote cellular transformation. We conclude that depending on the nature of cell transformation, Bid can be the decisive factor for apoptotic death of tumor cells in response to DNA-damaging anti-cancer regimens and can contribute to loss of clonogenicity independent of the $\mathrm{p} 53$ pathway. Bid hereby represents a common intermediate between death receptor- and DNA-damage-induced apoptosis. It may therefore, in certain tumor types, be a determinant for therapeutic outcome upon combined treatment with death receptor agonists and DNA-damaging anti-cancer regimens.

\section{Materials and methods}

\section{Cells and stimulation}

SV40-immortalized $\mathrm{Bid}^{-/-}$MEFs were originally from the laboratory of Dr S Korsmeyer (Harvard Medical School, Boston, MA, USA). The derivative $\mathrm{Bid}^{-/-} \mathrm{MEF}$ lines stably expressing empty vectors, the p53-targeting short hairpin RNA, Bid WT and Bid mutant complementary DNA (cDNA) were generated by retroviral transduction. Cells over-expressing Bcl-2 or the dnCaspase- 9 active site mutant C287A were manufactured similarly. Cell lines were cultured in Dulbecco's modified Eagle's medium supplemented with $8 \%$ fetal bovine serum, $2 \mathrm{~mm}$ L-glutamine and antibiotics. Human recombinant $\mathrm{TNF} \alpha$, cycloheximide and etoposide were purchased from SigmaAldrich (St Louis, MO, USA). For apoptosis assays, cells were stimulated with the indicated dosages of TNF $\alpha$ with cycloheximide, etoposide or IR for the indicated time periods at $37^{\circ} \mathrm{C}$ with $5 \% \mathrm{CO}_{2}$. Irradiation of cells was performed with a ${ }^{137} \mathrm{Cs}$ source (415 Ci; Von Gahlen Nederland BV, Zevenaar, The Netherlands) at an absorbed dose rate of approximately $0.66 \mathrm{~Gy} / \mathrm{min}$.

\section{Constructs}

The cDNAs encoding Bid mutants Bid D60E, Bid D75E, Bid D60E/D75E, Bid D55E/D60E/D75E, Bid Q58A, Bid S65A, 
Bid G70A/R71A, Bid G94E and Bid G94A were generated with a Quickchange Site-directed Mutagenesis Kit using fulllength human Bid cDNA as a template (Stratagene, La Jolla, CA, USA). The Bid w/o loop mutant was generated by inverse mutagenesis PCR from full-length human Bid cDNA with the following primers: forward, 5'-GGTTCAGGTTCATCAGGT CAAGAAGACATCATCCGGAATATT- $3^{\prime}$ and reverse, $5^{\prime}$-T GATGAACCTGAACCACCTGGCAGCTCGTGGCCCAGT GCGTC-3' (http://openwetware.org). The unstructured cleavage loop was hereby replaced by a 12-amino-acid stretch of glycine and serine residues, anticipated to display similar flexibility. WT Bid-, Bid mutant- and Bcl-2 cDNAs were cloned into the retroviral vector LZRS-IRES-Zeocin/pBR and dnCaspase-9 cDNA was cloned into the retroviral vector LZRS-IRES-GFP. Both vectors are derivatives of the LZRSpBMN-LacZ vector, which was provided by Dr GP Nolan (Stanford University School of Medicine, Stanford, CA, USA). RNAi for p53 was performed using shRNA (complementary sense and antisense oligonucleotides with p53-targeting sequence 5'-GTACATGTGTAATAGCTCC-3') cloned into the retroviral vector $\mathrm{pRETRO}$-SUPER, with a puromycin resistance cassette. All constructs were verified by dideoxynucleotide sequencing.

\section{Retroviral gene transduction}

To produce retrovirus, LZRS and pRETRO-SUPER constructs were transfected into the 293T human embryonic kidney cell-derived packaging cell line Phoenix-Eco, using FuGENE 6 transfection reagent according to the manufacturer's instructions (Roche Molecular Biochemicals, Mannheim, Germany). After $48 \mathrm{~h}$, virus-containing supernatant was harvested. Cells were incubated twice with fresh viral supernatant, for $8 \mathrm{~h}$ and overnight. The next day, viral supernatant was removed and cells were cultured in fresh medium. Cells were selected 3 days after transduction with $300 \mu \mathrm{g} / \mathrm{ml}$ zeocin (Invitrogen, Carlsbad, CA, USA) when LZRS-IRES-Zeocin/pBR constructs were used or with $10 \mu \mathrm{g} /$ $\mathrm{ml}$ puromycin (Sigma-Aldrich) when pRETRO-SUPER-p53 short hairpin RNA construct was used. Cells transduced with the LZRS-dnCaspase-9-IRES-GFP construct were sorted for GFP expression using a MoFlo high-speed cell sorter (Cytomation, Fort Collins, CO, USA). Cell lines that were compared side-by-side in apoptosis experiments were created in parallel in the same time frame, including empty vector and WT Bid-reconstituted control cell lines. The cell lines were validated by immunoblotting for p53 downregulation and Bid expression as shown.

\section{Apoptosis assay}

Assessment of the percentage of cells with cleaved caspase- 3 was used as a measure for apoptosis. After stimulation, all floating and adherent cells were collected and fixed with $4 \%$ paraformaldehyde in phosphate-buffered saline. Subsequently, cells were washed twice with $1 \%$ bovine serum albumin in phosphate-buffered saline and once with permeabilizing buffer (phosphate-buffered saline with $0.1 \%$ saponin and $0.5 \%$ bovine serum albumin). Next, cells were incubated for $20 \mathrm{~min}$ with permeabilizing buffer and stained for $1 \mathrm{~h}$ with rabbit antiactive caspase-3 antibody (1:50; BD Biosciences, Erembodegem, Belgium). Hereafter, cells were washed three times with

\section{References}

Anguissola S, Koehler B, O'Byrne R, Duessmann H, Cannon MD, Murray FE et al. (2009). Bid and calpains cooperate to trigger oxaliplatin-induced apoptosis of cervical carcinoma HeLa cells. Mol Pharmacol 76: 998-1010. permeabilizing buffer and stained for $1 \mathrm{~h}$ with AlexaFluor 647conjugated goat anti-rabbit immunoglobulin (1:100; Molecular Probes, Leiden, The Netherlands). After three more washes with permeabilizing buffer, cells were analyzed by flow cytometry in the FL4 channel.

\section{Clonogenic survival assay}

Cells were plated at increasing densities in $10-\mathrm{cm}$ dishes (250-12800 cells per dish). Once attached, cells were exposed to increasing concentrations of etoposide $(80-200 \mathrm{ng} / \mathrm{ml})$ or IR (2-10 Gy) and incubated for 14 days. Next, surviving colonies were fixed with $75 \% \mathrm{MeOH} / 25 \%$ acetic acid and stained with $50 \% \mathrm{MeOH} / 10 \%$ acetic acid $/ 0.2 \%$ Coomassie blue solution. The number of colonies was counted by visual inspection and the relative surviving fraction was determined with the ratio (colonies with dose $x \mathrm{~Gy} /$ colonies with dose $0 \mathrm{~Gy}$ ) $\times 1$.

\section{Immunoblotting}

Cells were lysed for 30 min in RIPA lysis buffer ( $1 \%$ Nonidet P-40, $50 \mathrm{mM}$ Tris- $\mathrm{HCl} \mathrm{pH} 7.5,150 \mathrm{~mm} \mathrm{NaCl}, 1 \%$ deoxycholate, $0.1 \%$ SDS, $5 \mathrm{~mm}$ EDTA and protease inhibitors) on ice. Cell lysates were subsequently cleared by centrifugation at $13000 \mathrm{~g}$ for $10 \mathrm{~min}$ at $4{ }^{\circ} \mathrm{C}$. Of the total cell lysates, samples containing $30 \mu \mathrm{g}$ total cellular protein were prepared, as determined by BCA assay (Thermo Scientific Pierce, Rockford, IL, USA). Proteins were separated on $4-12 \%$ NuPage Bis-Tris gradient gels (Invitrogen) in MES buffer, according to the manufacturer's instructions. Subsequent immunoblotting was performed as described (Tait et al., 2007). Proteins were detected with the following antibodies: sheep anti-p53 (Ab-7) pAb (1:2500; Oncogene Research Products, San Diego, CA, USA), rabbit anti-Bid pAb (1:250; rabbit serum; homemade but available from BD Biosciences), mouse anti-Bcl-2 mAb (1:1000; clone Bcl-2-100, mouse ascites fluid; Sigma-Aldrich), mouse anticaspase-9 mAb 9508 (1:1000; Cell Signaling Technology, Danvers, MA, USA) and mouse anti-Actin mAb C4, MAB1501R (1:10 000, Chemicon International, Temecula, CA, USA). Secondstep antibodies were horseradish peroxidase-conjugated rabbit anti-sheep immunoglobulin (1:7500), swine anti-rabbit immunoglobulin (1:7500) and rabbit anti-mouse immunoglobulin (1:7500, all from Dako A/S, Glostrup, Denmark). The enhanced chemiluminescence kit was from Pierce Biotechnology (Rockford, IL, USA).

\section{Conflict of interest}

The authors declare no conflict of interest.

\section{Acknowledgements}

This work was supported by grant NKI 2008-4110 from the Dutch Cancer Society. We thank Dr Atan Gross for MEF cell lines, Rogier Rooswinkel for data analysis, Inge Verbrugge, Bert van de Kooij and Rogier Rooswinkel for discussions and critical reading of the manuscript, and personnel of the flow cytometry facility of the Netherlands Cancer Institute for experimental assistance.
Brown JM, Wouters BG. (1999). Apoptosis, p53, and tumor cell sensitivity to anticancer agents. Cancer Res 59: 1391-1399.

Chipuk JE, Green DR. (2006). Dissecting p53-dependent apoptosis. Cell Death Differ 13: 994-1002. 
Chou JJ, Li H, Salvesen GS, Yuan J, Wagner G. (1999). Solution structure of BID, an intracellular amplifier of apoptotic signaling. Cell 96: 615-624.

Cirman T, Oresic K, Mazovec GD, Turk V, Reed JC, Myers RM et al. (2004). Selective disruption of lysosomes in HeLa cells triggers apoptosis mediated by cleavage of Bid by multiple papain-like lysosomal cathepsins. J Biol Chem 279: 3578-3587.

Erlacher M, Michalak EM, Kelly PN, Labi V, Niederegger H, Coultas L et al. (2005). BH3-only proteins Puma and Bim are rate-limiting for gamma-radiation- and glucocorticoid-induced apoptosis of lymphoid cells in vivo. Blood 106: 4131-4138.

Gross A, Yin XM, Wang K, Wei MC, Jockel J, Milliman C et al. (1999). Caspase cleaved BID targets mitochondria and is required for cytochrome c release, while BCL-XL prevents this release but not tumor necrosis factor-R1/Fas death. J Biol Chem 274: 1156-1163.

Gross A. (2006). BID as a double agent in cell life and death. Cell Cycle 5: 582-584.

Guo Y, Srinivasula SM, Druilhe A, Fernandes-Alnemri T, Alnemri ES. (2002). Caspase-2 induces apoptosis by releasing proapoptotic proteins from mitochondria. J Biol Chem 277: 13430-13437.

Kamer I, Sarig R, Zaltsman Y, Niv H, Oberkovitz G, Regev L et al. (2005). Proapoptotic BID is an ATM effector in the DNA-damage response. Cell 122: 593-603.

Kaufmann T, Tai L, Ekert PG, Huang DC, Norris F, Lindemann RK et al. (2007). The BH3-only protein bid is dispensable for DNA damage- and replicative stress-induced apoptosis or cell-cycle arrest. Cell 129: 423-433.

Koehler B, Anguissola S, Concannon CG, Rehm M, Kogel D, Prehn JH. (2008). Bid participates in genotoxic drug-induced apoptosis of HeLa cells and is essential for death receptor ligands' apoptotic and synergistic effects. PLoS One 3: e2844.

Krajewska M, Zapata JM, Meinhold-Heerlein I, Hedayat H, Monks A, Bettendorf $\mathrm{H}$ et al. (2002). Expression of Bcl-2 family member Bid in normal and malignant tissues. Neoplasia 4: 129-140.

Lam M, Dubyak G, Chen L, Nunez G, Miesfeld RL, Distelhorst CW. (1994). Evidence that BCL-2 represses apoptosis by regulating endoplasmic reticulum-associated $\mathrm{Ca} 2+$ fluxes. Proc Natl Acad Sci USA 91: 6569-6573.

Letai A, Bassik MC, Walensky LD, Sorcinelli MD, Weiler S, Korsmeyer SJ. (2002). Distinct BH3 domains either sensitize or activate mitochondrial apoptosis, serving as prototype cancer therapeutics. Cancer Cell 2: 183-192.

Luo X, Budihardjo I, Zou H, Slaughter C, Wang X. (1998). Bid, a Bcl2 interacting protein, mediates cytochrome $\mathrm{c}$ release from mitochondria in response to activation of cell surface death receptors. Cell 94: 481-490.

Mandic A, Viktorsson K, Strandberg L, Heiden T, Hansson J, Linder S et al. (2002). Calpain-mediated Bid cleavage and calpainindependent Bak modulation: two separate pathways in cisplatininduced apoptosis. Mol Cell Biol 22: 3003-3013.

McDonnell JM, Fushman D, Milliman CL, Korsmeyer SJ, Cowburn D. (1999). Solution structure of the proapoptotic molecule BID a structural basis for apoptotic agonists and antagonists. Cell 96: 625-634

Michalak EM, Villunger A, Adams JM, Strasser A. (2008). In several cell types tumour suppressor p53 induces apoptosis largely via Puma but Noxa can contribute. Cell Death Differ 15: 1019-1029.

Oberkovitz G, Regev L, Gross A. (2007). Nucleocytoplasmic shuttling of BID is involved in regulating its activities in the DNA-damage response. Cell Death Differ 14: 1628-1634.

Ploner C, Kofler R, Villunger A. (2008). Noxa: at the tip of the balance between life and death. Oncogene 27(Suppl 1): S84-S92.

Ren D, Tu H-C, Kim H, Wang GX, Bean GR, Takeuchi O et al. (2010). BID, BIM, and PUMA are essential for activation of the BAX- and BAK-dependent cell death program. Science 330: 1390-1393.

Sarig R, Zaltsman Y, Marcellus RC, Flavell R, Mak TW, Gross A. (2003). BID-D59A is a potent inducer of apoptosis in primary embryonic fibroblasts. J Biol Chem 278: 10707-10715.
Sax JK, Fei P, Murphy ME, Bernhard E, Korsmeyer SJ, El Deiry WS. (2002). BID regulation by p53 contributes to chemosensitivity. Nat Cell Biol 4: 842-849.

Schmitt CA, Rosenthal CT, Lowe SW. (2000). Genetic analysis of chemoresistance in primary murine lymphomas. Nat Med 6: 1029-1035.

Shelton SN, Shawgo ME, Robertson JD. (2009). Cleavage of Bid by executioner caspases mediates feed forward amplification of mitochondrial outer membrane permeabilization during genotoxic stressinduced apoptosis in Jurkat cells. J Biol Chem 284: 11247-11255.

Simmen T, Aslan JE, Blagoveshchenskaya AD, Thomas L, Wan L, Xiang Y et al. (2005). PACS-2 controls endoplasmic reticulummitochondria communication and Bid-mediated apoptosis. EMBO J 24: 717-729.

Slee EA, Keogh SA, Martin SJ. (2000). Cleavage of BID during cytotoxic drug and UV radiation-induced apoptosis occurs downstream of the point of Bcl-2 action and is catalysed by caspase-3: a potential feedback loop for amplification of apoptosisassociated mitochondrial cytochrome c release. Cell Death Differ 7: $556-565$.

Strasser A, Harris AW, Jacks T, Cory S. (1994). DNA damage can induce apoptosis in proliferating lymphoid cells via p53-independent mechanisms inhibitable by Bcl-2. Cell 79: 329-339.

Tait SW, de Vries E, Maas C, Keller AM, D'Santos CS, Borst J. (2007). Apoptosis induction by Bid requires unconventional ubiquitination and degradation of its N-terminal fragment. $J$ Cell Biol 179: 1453-1466.

Tan KO, Tan KM, Yu VC. (1999). A novel BH3-like domain in BID is required for intramolecular interaction and autoinhibition of pro-apoptotic activity. J Biol Chem 274: 23687-23690.

Valentijn AJ, Gilmore AP. (2004). Translocation of full-length Bid to mitochondria during anoikis. J Biol Chem 279: 32848-32857.

Villunger A, Michalak EM, Coultas L, Mullauer F, Bock G, Ausserlechner MJ et al. (2003). p53- and drug-induced apoptotic responses mediated by $\mathrm{BH} 3$-only proteins puma and noxa. Science 302: $1036-1038$

Wang X. (2001). The expanding role of mitochondria in apoptosis. Genes Dev 15: 2922-2933.

Ward MW, Rehm M, Duessmann H, Kacmar S, Concannon CG, Prehn JH. (2006). Real time single cell analysis of Bid cleavage and Bid translocation during caspase-dependent and neuronal caspaseindependent apoptosis. J Biol Chem 281: 5837-5844.

Werner AB, Tait SW, de Vries E, Eldering E, Borst J. (2004). Requirement for aspartate-cleaved bid in apoptosis signaling by DNA-damaging anti-cancer regimens. $J$ Biol Chem 279: 28771-28780.

Willis SN, Fletcher JI, Kaufmann T, van Delft MF, Chen L, Czabotar $\mathrm{PE}$ et al. (2007). Apoptosis initiated when $\mathrm{BH} 3$ ligands engage multiple Bcl-2 homologs, not Bax or Bak. Science 315: 856-859.

Yu J, Zhang L, Hwang PM, Kinzler KW, Vogelstein B. (2001). PUMA induces the rapid apoptosis of colorectal cancer cells. Mol Cell 7: $673-682$.

Zha J, Weiler S, Oh KJ, Wei MC, Korsmeyer SJ. (2000). Posttranslational N-myristoylation of BID as a molecular switch for targeting mitochondria and apoptosis. Science 290: 1761-1765.

Zinkel SS, Hurov KE, Gross A. (2007). Bid plays a role in the DNA damage response. Cell 130: 9-10.

Zinkel SS, Hurov KE, Ong C, Abtahi FM, Gross A, Korsmeyer SJ. (2005). A role for proapoptotic BID in the DNA-damage response. Cell 122: 579-591.

Zinkel SS, Ong CC, Ferguson DO, Iwasaki H, Akashi K, Bronson RT et al. (2003). Proapoptotic BID is required for myeloid homeostasis and tumor suppression. Genes Dev 17: 229-239.

(c) This work is licensed under the Creative Commons Attribution-NonCommercial-No Derivative Works 3.0 Unported License. To view a copy of this license, visit http://creativecommons.org/licenses/by-nc-nd/3.0/ 